\title{
Benefits of Using Pairwise Trajectory Management in the Central East Pacific
}

\author{
Ryan Chartrand, Kathryn Ballard \\ Of National Aeronautics and Space Administration \\ Langley Research Center \\ Hampton, Virginia USA
}

\section{INTRODUCTION}

Future traffic predictions indicate there will be continued growth in oceanic operations. Even with recent improvements to oceanic surveillance and communications systems, required separation standards in oceanic airspace are still large enough to cause aircraft operational inefficiencies. These inefficiencies include flights being unable to operate at their desired altitudes and speeds for extended periods of time, flights being unable to operate on their desired routes, and flights required to change altitudes for crossing traffic. These system inefficiencies increase flight time and fuel burn.

PTM (Pairwise Trajectory Management) is designed to allow aircraft to resolve a specific traffic conflict (or conflicts), identified by the ground system, with a potentially more efficient spacing assignment. A complete description of the PTM concept can be found in the RTCA operational service description document [1]. The controller, using ground-based decision-support automation, issues a pair-specific PTM clearance to a PTM equipped aircraft. When accepted, this PTM clearance will resolve the conflict for the specific pair of aircraft (and the ground system will display that the conflict has been resolved). The PTM clearance requires the flight crew of the PTM equipped aircraft to use their Automatic Dependent Surveillance-Broadcast (ADS-B)-enabled on-board PTM avionics to manage their spacing relative to the engaged aircraft. The PTM avionics will provide speed guidance to ensure spacing distances are maintained that are no closer than the PTM minimum spacing distance. When the controller assesses (with ground automation system support) that the PTM operation is no longer required, the controller issues a clearance to terminate the PTM operation.

PTM will support same track operations (typically found in oceanic organized track systems) and crossing track operations (typically found with oceanic user preferred routes). Due to the reduced PTM minimum spacing distance (compared to current ground based spacing distances), the PTM aircraft may not be required to modify their current speed in many crossing situations. PTM should save fuel and reduce delays by improving operations that increase time on an aircraft's optimal trajectory (track and altitude). The airborne managed distance can allow for higher throughput and generally more efficient aircraft operations.

PTM is employed, depending on local constraints and traffic characteristics, to support several different types of operations. For example, a PTM clearance could be used to resolve a short-term conflict (such as one aircraft climbing through the altitude of another) or could be used for an extended period of time (same track, same altitude).

The availability of a PTM resolution to a conflict does not necessarily make it the preferred option for the controller. PTM is not intended to take away the controller's discretion in managing the traffic in their sector.

There are also times when PTM is not an available option for the controller. One example of this is when the two aircraft are out of ADS-B range (estimated) from each other. Additionally, some conditions may cause the flight crew to refuse a PTM clearance. This could include situations when PTM operations may require the flight crew to fly a speed that is faster or slower than the aircraft is capable of maintaining or the requirements for the PTM avionics to provide a guidance solution are not met.

In addition, certain traffic encounter geometries may prevent the availability of PTM to be used by either the controller or flight crew (e.g., head on traffic encounter geometries).

\section{EXPERIMENT DESIGN}

A fast-time experiment to support the development and evaluation of the PTM concept of operations was conducted at the National Aeronautics and Space Administration (NASA) Langley Research Center. The focus of this experiment was to evaluate the benefits of PTM in the Central East Pacific (CEP) oceanic airspace region. Fuel burn, time on optimum altitude, and altitude requests were measured to assess benefits of PTM. This experiment considered the parameters of ADS-B IN equipage, PTM equipment, and separation standard. ADS-B IN equipage was varied as a percentage of the aircraft in the airspace. The percent of aircraft equipped with ADS-B IN were set at $10 \%, 20 \%, 45 \%, 70 \%$, and $80 \%$. The assignment of which aircraft would be equipped with ADS-B IN was done randomly. However, once an aircraft was equipped with ADSB IN at any equippage level it was also equipped at every higher equippage level. Since the distribution of equipped versus unequipped aircraft could have an impact on the resulting benefit to the system, four iterations were done on the equipage distribution. Each iteration used the same initial conditions for all aircraft but changed which $10 \%$, and higher percentages, of the aircraft was equipped with ADS-B IN. It 
was assumed that all aircraft in the airspace would be equipped with ADS-B OUT, given the Federal Aviation Administration (FAA) mandate on ADS-B OUT equipment being installed by 2020. The last parameter of separation standard was applied only to those aircraft which were equipped with PTM. The PTM equipped aircraft were able to use a separation standard of 5,10 , or 15 nautical miles (NM). The separation standard applied to non-PTM equipped aircraft was $80 \mathrm{NM}$.

To evaluate PTM benefits, the test cases were compared to a baseline airspace that modeled current day operations and to an unconstrained airspace that modeled an idealized airspace where all aircraft fly their preferred routes. The separation standard of the baseline was set to 80NM to fit with current figures of typical separation in the CEP and no aircraft were equipped with PTM. In the unconstrained case, the separation standard was $0 \mathrm{NM}$, and aircraft flew their optimal paths, ignoring traffic aircraft.

To model the density and distribution of aircraft within the $\mathrm{CEP}$, recorded traffic data were received from the FAA and converted into scenario files that could be used in the simulation. This allowed for the experiment to use traffic patterns that are comparable to what aircraft in real operations would experience. Sixty-three different days were selected from the FAA data to use as independent traffic replicates. These replicates were spaced equally throughout a year, so that seasonal variations in traffic were captured. Due to some small variations within the simulation environment two duplicates of the entire experiment matrix were run and then averaged together. This experiment matrix resulted in a total of 7,686 scenarios that were run for data collection.

This experiment used a simulation platform called TMX (Traffic Manager). TMX has been used for similar oceanic experiments providing an oceanic operating environment including: a pilot model capable of determining and making altitude change requests, an air traffic controller model which can receive, analyze, and respond to altitude change requests, a Controller Pilot Data Link Communication (CPDLC) system for sending requests and clearances between aircraft and the ground, an Automatic Dependent Surveillance-Broadcast (ADS-B) model, realistic oceanic wind fields, the oceanic track systems, oceanic airspace boundaries, and oceanic separation rules. The oceanic environment and separation rules required updating to support this experiment to reflect operations specific to the CEP.

\section{RESULTS}

The data from this experiment were analyzed to observe the benefits experienced by unequipped aircraft and by PTM equipped aircraft. By introducing the PTM operation into the airspace, it is desired to not introduce a burden on those aircraft that choose not to equip with the new technology. Non-PTM equipped aircraft experienced a small improvement in overall efficiency with the introduction of PTM operations. The PTM equipped aircraft showed a fuel savings of approximately 130 pounds per hour, and this level of fuel savings equates to a fuel burn reduction of over $1 \%$.
Several dependent measures were compared between the baseline airspace, PTM test case airspace, and the unconstrained airspace to quantify the benefit of PTM.

\section{Fuel Burn}

The total fuel burned by each aircraft was normalized by flight time and compared directly with the corresponding aircraft in the baseline airspace. This difference in fuel use, Delta Fuel Burn (lbs/hr), was then averaged over all flights in a given scenario. The fuel burn was also transformed into a percentage of fuel saved over the baseline.

Table 1 gives the mean fuel burn savings by airspace.

$$
\text { Table 1: Fuel Savings over Current Day }
$$

\begin{tabular}{lcc}
$\begin{array}{l}\text { Airspace } \\
\text { Configuration }\end{array}$ & $\begin{array}{l}\text { Mean Fuel Burn } \\
\text { Savings (std. dev) } \\
{[\mathrm{lbs} / \mathrm{hr}]}\end{array}$ & $\begin{array}{l}\text { Mean Percent } \\
\text { Savings (std. dev) } \\
{[\%]}\end{array}$ \\
\hline PTM: Unequipped & $5.2(84.5)$ & $0.1(0.8)$ \\
PTM: PTM Equipped & $127.3(193.4)$ & $1.4(1.8)$ \\
Unconstrained & $139.5(204.4)$ & $1.5(1.9)$
\end{tabular}

PTM Equipped aircraft save on average $127.3 \mathrm{lbs} / \mathrm{hr}$ or $1.4 \%$ per hour over current day operations. PTM Equipped fuel savings are close to the savings seen by the unconstrained airspace $(139.5 \mathrm{lbs} / \mathrm{hr}, 1.5 \%$ on average). By introducing the PTM operation into the airspace, it is not desired to introduce a burden on those aircraft that choose not to equip with the new technology. Unequipped aircraft see a small benefit of $5.2 \mathrm{lbs} / \mathrm{hr}$ or $0.1 \%$ savings on average above their baseline counterparts. This small savings is a result of unequipped aircraft being able to take advantage of a PTM equipped aircraft that would have blocked a request, but is now able to be approved due to PTM. PTM operations can be initiated to benefit either the PTM equipped aircraft or a non-PTM equipped aircraft.

Figure 1 shows the distributions of the PTM Airspace, broken down into PTM Equipped and Unequipped, and the Unconstrained Airspace, relative to the Current Day fuel burn. Positive values of Delta Fuel Burn mean those aircraft saved fuel over the current day baseline. Unequipped aircraft have a distribution centered around $0 \mathrm{lbs} / \mathrm{hr}$ meaning unequipped aircraft tend to burn about the same amount of fuel as current day aircraft, while a few save more fuel and a few burn more fuel. PTM Equipped aircraft have a distribution mostly above 0 , meaning PTM saves fuel over current day. The PTM Equipped distribution also lines up with the Unconstrained distribution fairly well implying PTM saves almost as much fuel as the Unconstrained aircraft do. 
Fuel Savings over Current Day Airspace

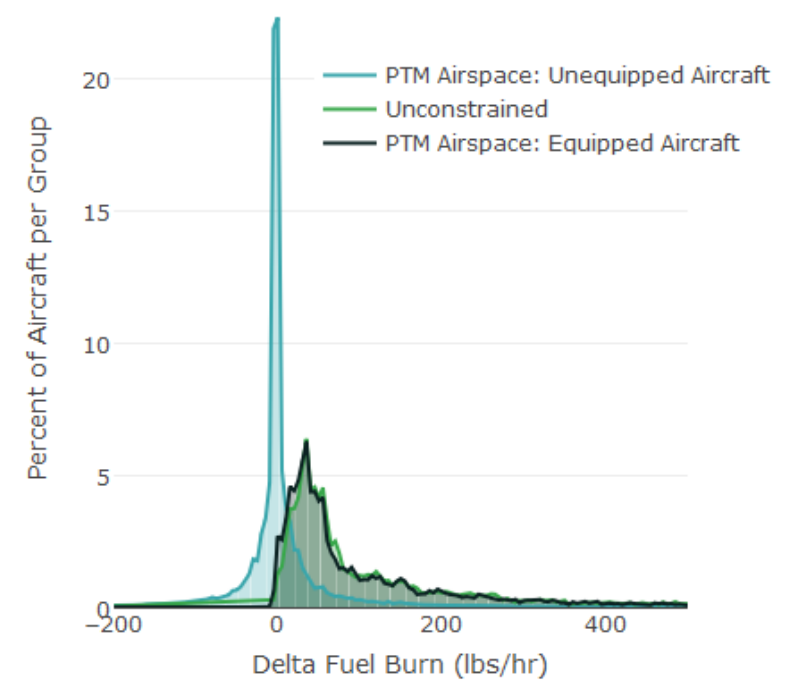

Figure 1: Distribution of Fuel Savings over Current Day

For a deeper look at how separation standard and airspace equipage affect fuel savings, a two-way analysis of variance (ANOVA) was conducted on delta fuel burn of the PTM airspace compared to the current day airspace. If one of these variables was significant ( $\mathrm{p}$-value $<0.05)$, further testing using the Tukey-Kramer Honest Significant Difference (HSD) test was done. This test is used to determine which levels of a variable are different from the rest.

Breaking down PTM equipped aircraft by the tested separation standards and equipage levels, there was a statistical difference between separation standards but not a practical one (p-value < 0.001). Scenarios with a 5NM separation saw an average savings of $129.2 \mathrm{lbs} / \mathrm{hr}$ while the $15 \mathrm{NM}$ separation scenario saw $125.2 \mathrm{lbs} / \mathrm{hr}$ of savings on average, only 4 pounds less.

Unequipped aircraft were influenced by the equipage level of the scenario ( $\mathrm{p}$-value $<0.001$ ). As more traffic aircraft were equipped with PTM, the unequipped aircraft saw more fuel savings - until $70 \%$ equipage when the trend plateaus (fuel savings of $2 \mathrm{lbs} / \mathrm{hr}$ at $10 \%$ up to 12 and $13 \mathrm{lbs} / \mathrm{hr}$ at 70 and $80 \%$ equipage). This fuel savings is a result of PTM operations that were initiated specifically to allow an unequipped aircraft to change altitude. As the PTM equipage increases in the airspace, there are more opportunities for an unequipped aircraft to be near a PTM aircraft and be able to benefit from this new operation.

Using partition trees to analyze the relationship between measures of interest and fuel burn showed that separating the data into PTM equipped or unequipped aircraft reduces variability in fuel burn by the greatest amount. This method also revealed that other variables, characteristics of the aircraft or simulation, influenced fuel burn more than separation standard or airspace equipage; how far an aircraft was from its desired altitude at the start of the simulation (Delta Requested Flight Level) and the type of aircraft were included by the tree while separation and equipage were not. The partition tree is shown in Figure 2, with fuel savings in the leaves.

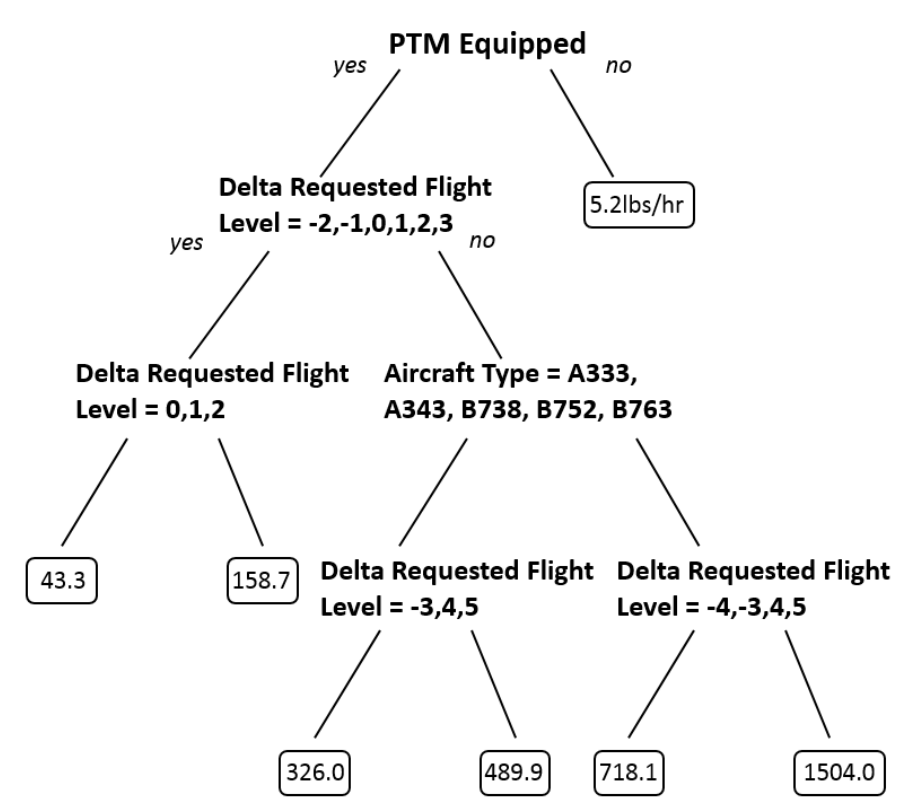

Figure 2: Fuel Savings Partition Tree

Aircraft type was one variable that accounted for variability in fuel savings in $\mathrm{lbs} / \mathrm{hr}$. This influence disappeared when looking at percent fuel savings since fuel burn is relative to aircraft size and type, some aircraft typically carry and burn more fuel than others. figures 3 and 4 show fuel savings by aircraft type in $\mathrm{lbs} / \mathrm{hr}$ then percent savings. The trend of an increase in savings as size increases is leveled out in figure 4 (\% savings). The aircraft in the Small group saved pounds of fuel in relatively low values compared to other groups, but looking at the percent saved, the Small group seems to get a large benefit.

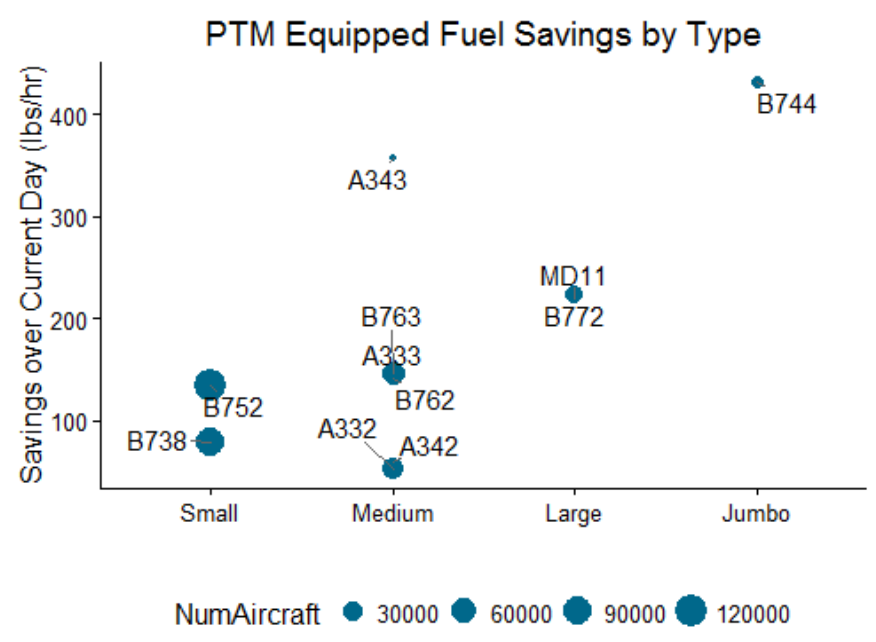

Figure 3: PTM Equipped Fuel Savings (lbs/hr) by Aircraft Type, Grouped by Size 


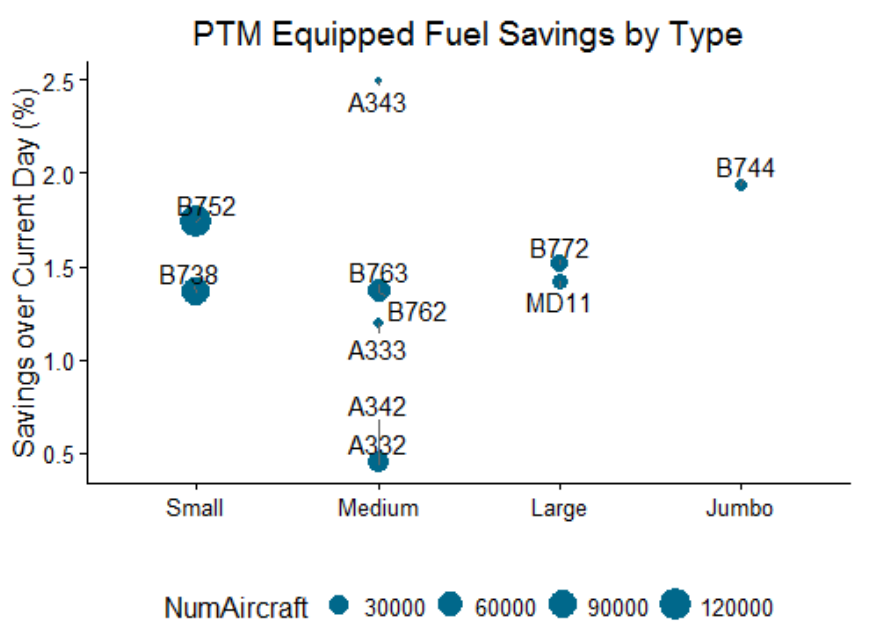

Figure 4: PTM Equipped Fuel Savings (\%) by Aircraft Type, Grouped by Size

Certain aircraft types generally carry and burn more fuel than others. Even when controlling for that fact by looking at savings as a percent of the baseline fuel burn, the savings vary by aircraft. Most PTM Equipped aircraft in the simulation saved between 1 and 2 percent per hour on average which can add up over a long oceanic flight. Table 2 summarizes the fuel savings plotted above by type, grouped by size.

\section{Table 2: Fuel Savings over Current Day by Aircraft Type and Size}

\begin{tabular}{|c|c|c|c|}
\hline Aircraft Type & $\begin{array}{r}\text { Mean Delta } \\
\text { Fuel Burn } \\
(\mathrm{lbs} / \mathrm{hr})\end{array}$ & $\begin{array}{c}\text { Mean } \\
\text { Percent } \\
\text { Savings }(\%)\end{array}$ & $\begin{array}{r}\text { Number } \\
\text { of } \\
\text { Aircraft }\end{array}$ \\
\hline $\begin{array}{l}\text { Small: narrow } \\
\text { body, } 2 \text { engine }\end{array}$ & 109.5 & 1.6 & 216,426 \\
\hline B738 & 78.4 & 1.4 & 95,607 \\
\hline B752 & 134.0 & 1.7 & 120,819 \\
\hline $\begin{array}{l}\text { Medium: wide } \\
\text { body, } 2 \text { engine }\end{array}$ & 107.7 & 0.98 & 101,838 \\
\hline A332 & 53.2 & 0.45 & 42,990 \\
\hline A342 & 59.1 & 0.44 & 75 \\
\hline B762 & 141.8 & 1.4 & 1,890 \\
\hline A333 & 146.0 & 1.2 & 2,436 \\
\hline B763 & 147.2 & 1.4 & 54,294 \\
\hline A343 & 357.0 & 2.5 & 153 \\
\hline $\begin{array}{l}\text { Large: wide body, } \\
2+\text { engine }\end{array}$ & 224.2 & 1.5 & 36,849 \\
\hline B772 & 223.3 & 1.5 & 22,266 \\
\hline MD11 & 225.5 & 1.4 & 14,583 \\
\hline $\begin{array}{l}\text { Jumbo: wide } \\
\text { body, } 4 \text { engine }\end{array}$ & 431.8 & 1.9 & 7,476 \\
\hline B744 & 431.8 & 1.9 & 7,476 \\
\hline
\end{tabular}

Another influential variable identified by the partition tree was delta from requested flight level, which is how far from optimum altitude a flight was at the start of the simulation, measured in thousands of feet. Aircraft loaded further from optimum see more fuel savings than those loaded closer to their optimum altitude. Figure 5 shows that trend. When flights are loaded far from their preferred altitude, the aircraft may suffer reduced fuel burn performance until they attain their optimum altitude.

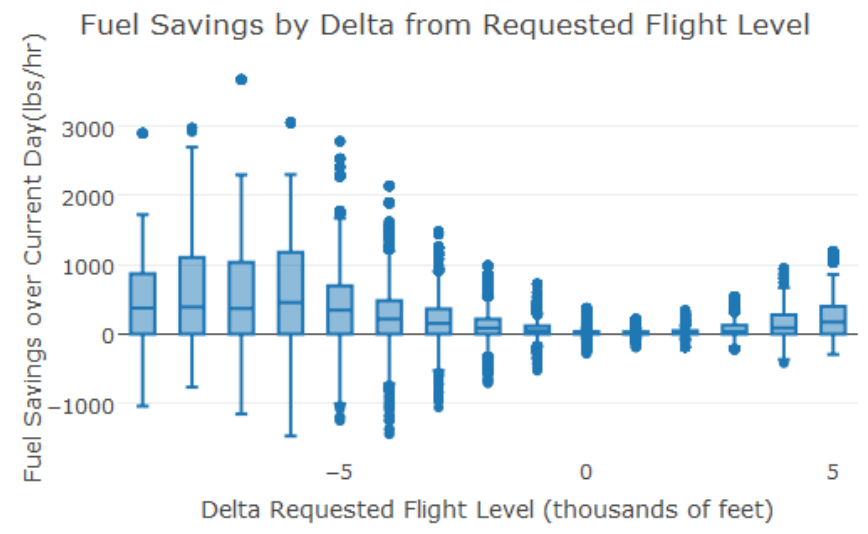

Figure 5: Fuel Savings by Delta Requested Flight Level

The aircraft's delta from requested flight level gives information on altitude at the start of the simulation. Time on optimum altitude is a related variable that measures the amount of time a flight is on its optimum altitude. This is converted to a percent of the time on optimum because flights have different total flight times.

\section{Percent of Flight on Optimum Altitude}

Differences in aircraft's time on optimum altitude between the three airspaces are another measure of interest for the benefits story. There was a significant difference in the mean percent time on optimum altitude between all of the simulated airspaces (ANOVA p-value $<0.001$, Tukey's test p-values all < 0.001). PTM Equipped aircraft in the PTM Airspace average $91.3 \%$ of their flights on their optimum altitude which is not far from the average for aircraft in the Unconstrained Airspace, 97\%. The average for flights in the current CEP airspace is $33.3 \%$ on optimum and unequipped aircraft in the PTM airspace are on optimum $34.3 \%$ on average (similar to fuel savings, unequipped aircraft do not see a negative impact by introducing PTM into the airspace). Figure 6 shows the distributions of percent of flight on optimum altitude. 


\section{Percent of Time on Optimum Altitude}

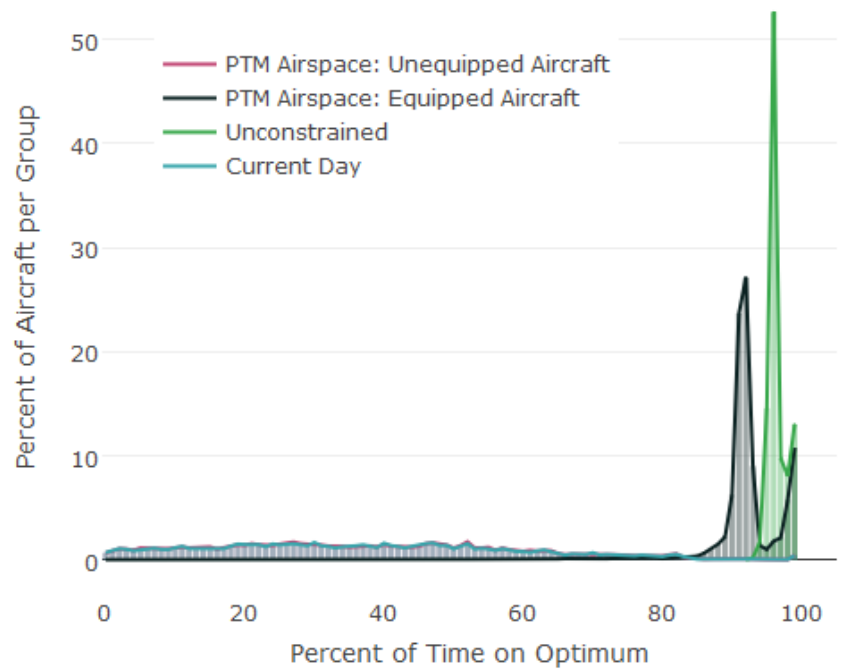

Figure 6: Percent of Flight Time on Optimum Altitude, by Airspace

\section{Altitude Requests}

Another metric of interest is the altitude requests made by the pilot model. PTM equipped aircraft as part of the algorithm make more frequent requests than unequipped aircraft. Each aircraft with PTM made an average of 3.2 unique requests during their flight compared to 1.7 unique requests for unequipped flights.

Reasonable requests made by unequipped aircraft are sometimes denied to add realism to the simulation, as pilots typically do not make a large number of requests in the current day CEP airspace. Equipped or unequipped, there are requests that are denied for operational reasons, such as not having separation at the requested altitude or an altitude in between, or the other aircraft is in the middle of a procedure. PTM equipped aircraft see their requests denied for operational reasons in $5.5 \%$ of requests while unequipped aircraft were denied $16.9 \%$ of the time (current day averages $23.4 \%$ ). When looking at separation standard and equipage levels, familiar trends appear; PTM equipped aircraft get more benefit as separation decreases and unequipped aircraft get a small increase in benefit as the equipage or aircraft in the airspace increases.

\section{CONCLUSIONS}

PTM technology does provide benefit to the CEP in terms of fuel burn reduction, increased time on optimum altitude, and more approved altitude requests. Compared to the current day airspace, flights that are equipped with PTM save $129.2 \mathrm{lbs} / \mathrm{hr}$ (or $1.4 \%$ ) on average with a 5NM separation. The amount of time flights get to spend at their optimum altitude greatly increases for PTM equipped aircraft compared to flights in the current day airspace. Altitude requests made by aircraft equipped with PTM are also denied much less often than requests by unequipped aircraft.

Follow on fast time experiments are planned to investigate other airspace regions: North Atlantic Organized Track System (NATOTS), Pacific Organized Track System (PACOTS), West Atlantic Route System (WATRS), along with further investigation in the Central East Pacific. NASA is also planning human-in-the-loop (HITL) experiments with oceanic line pilots to investigate the feasibility and acceptability of proposed PTM flight crew procedures and an airborne PTM human machine interface.

\section{REFERENCES}

[1] RTCA (2016). Advanced-interval management (A-IM) pairwise trajectory management (PTM) operational service description. Manuscript in preparation. 